\title{
Olanzapine and quetiapine in the prevention of a new mood episode in women with bipolar disorder during the postpartum period: a retrospective cohort study
}

\author{
Faruk Uguz, (iD Aysegul Kirkas iD \\ Department of Psychiatry, Meram Faculty of Medicine, Necmettin Erbakan University, Konya, Turkey.
}

\begin{abstract}
Objective: To examine whether olanzapine and quetiapine are useful in the prevention of a new mood episode during the postpartum period.

Methods: Data on 23 patients ( $n=14$ for olanzapine and $n=9$ for quetiapine) with bipolar disorder who met the criteria for this study were retrospectively gathered. The diagnosis of bipolar disorder was determined by means of the DSM-IV.

Results: The mean follow-up period was 33.95 \pm 12.07 weeks. Six (26.1\%) of 23 patients experienced recurrent mood episodes during the postpartum period. Four of these six patients were taking olanzapine and two were taking quetiapine. Patients with recurrent mood episodes had a significantly stronger family history of bipolar disorder, higher number of past episodes, and earlier onset and longer duration of illness compared to patients without recurrent mood episodes.

Conclusion: Monotherapy with olanzapine or quetiapine can be considered as an alternative to mood stabilizers in preventing the development of new mood episodes after childbirth.
\end{abstract}

Keywords: Postpartum period; olanzapine; quetiapine; bipolar disorder

\section{Introduction}

Bipolar disorder (BD) is a major psychiatric diagnosis that can affect functional capacity and lead to hospitalization. The lifetime prevalence of bipolar spectrum disorders has been reported to be $2.4 \% .^{1}$ Studies have suggested that the postpartum period is associated with increased risk of recurrence of mood epsiodes in women with $\mathrm{BD} .^{2,3}$ Moreover, Di Florio et al. ${ }^{4}$ reported that the first episode of BD occurred after childbirth in $28 \%$ of patients. New mood episodes can be disruptive not only for patients, but also for their infants and family relationships. ${ }^{5}$ It has been reported that inadequate clinical management or discontinuation of medication can result in rapid relapses in mood episodes. ${ }^{6}$ Interruption of medication during the postpartum period can also enhance the risk of relapse. ${ }^{7}$ Overall, $52-75 \%$ of women with BD have a history of one or more postpartum mood episodes. ${ }^{2,3,8}$ A recent metaanalysis indicated that the risk of recurrence of mood episodes was about twofold lower in patients using prophylactic pharmacotherapy during the postpartum period compared to patients who remained medication-free. ${ }^{9}$

Despite the wide variety of pharmacological options available for non-perinatal women, lactation is a major challenging factor in the management of BD during the postpartum period. ${ }^{10}$ It is well known that all psychotropic

Correspondence: Faruk Uguz, Necmettin Erbakan Üniversitesi Meram Ťip Fakültesi, Psikiyatri Anabilim Dali, Meram, 42080, Konya, Turkey.

E-mail: farukuguz@gmail.com

Submitted Oct 23 2020, accepted Jan 27 2021, Epub Apr 052021. drugs excrete into breast milk to varying levels. On the other hand, many mothers would like to breastfeed their infants due to the undeniable benefits of this practice. Nonetheless, the possibility of social, functional, and clinical problems secondary to a new mood episode creates a dilemma about prophylactic treatment during the postpartum period in many mothers and their families. Most authors and guidelines accept a high risk of recurrence of mood episodes in this period, and recommend weighing the risk-benefit balance between potential effects of medications versus those of mood episodes on the infant and the patient. ${ }^{7}$

The primary medications used in management of patients with BD are mood stabilizers and antipsychotics. Lithium has been reported to be effective in preventing new mood episodes in postpartum women. ${ }^{11,12}$ Although there is no clear evidence to contraindicate lithium therapy during lactation, relatively poor safety parameters in breastfed infants and the requirement of monitoring the breastfed infant's lithium level and thyroid and renal function lead to concerns and challenges regarding its use in this group of patients. ${ }^{13}$ The safety profile of valproate appears to be better than that of lithium during lactation; however, limited available data suggest that valproate may not be useful as prophylaxis during the postpartum period. ${ }^{11}$ Some guidelines recommend that
How to cite this article: Uguz F, Kirkas A. Olanzapine and quetiapine in the prevention of a new mood episode in women with bipolar disorder during the postpartum period: a retrospective cohort study. Braz J Psychiatry. 2021;43:617-620. http://dx.doi.org/ 10.1590/1516-4446-2020-1629 
the second-generation antipsychotics, olanzapine and quetiapine in particular, be considered for use by postpartum women due to their good safety profiles. ${ }^{14,15}$ However, scientific evidence on their efficacy in preventing new mood episodes in postpartum women is inadequate. This study presents 12 years of clinical data on the use of olanzapine and quetiapine in preventing recurrence of mood episodes during the postpartum period.

\section{Methods}

The data for this retrospective cohort study were collected from the clinical records of 23 patients who were admitted between January 2008 and March 2020 to the outpatient psychiatry clinic of a university hospital with a diagnosis of BD according to a structured psychiatric interview. The inclusion criteria were maternal age $\geqslant 18$ years, no active episode during the first psychiatric interview, use of olanzapine or quetiapine alone during the postpartum period, and at least 12 weeks of follow-up period. The exclusion criteria were: 1) comorbid axis I psychiatric disorders; 2) a history of schizophrenia or related psychoses; 3) alcohol or substance use disorders; 4) cerebrovascular diseases, severe infections, uncontrolled endocrine abnormalities, or cardiovascular diseases during the follow-up period; 5) severe medical problems in the infant; 6) first admission to the psychiatry outpatient clinic before the 30th gestational week; and 7) diagnosis of BD of less than 1 year's duration.

The antipsychotic medications were administered with the consent of the patients and their first-degree relatives. In addition, written informed consent for the presentation of their data in the scientific literature was obtained from all patients. Owing to its retrospective design, the current study did not interfere with patient management. The structured psychiatric interview was carried out with the Structured Clinical Interview for the DSM-IV (SCID-I). ${ }^{16}$ The follow-up psychiatric evaluations were carried out at least once a month. The SCID-I and follow-up interviews were conducted by a psychiatrist with experience in the diagnosis of psychiatric disorders, management of psychiatric disorders during the perinatal period, and use of diagnostic instruments.

The data were analyzed using SPSS version 16.0 for Windows. Categorical variables and continuous variables in patient groups with and without new mood episodes during the follow-up periods were compared with a chisquare test (if necessary, with Fisher's exact test) and $t$ test, respectively. Statistical significance was accepted at $p<0.05$.

The study procedure was approved by the local ethics committee.

\section{Results}

The mean age of the 23 participants was $30.39 \pm 4.42$ years. All were married and most $(n=21,91.3 \%)$ were unemployed. Sixteen $(69.6 \%)$ patients had completed primary education. Ten patients $(43.5 \%)$ were primiparous. Seven $(30.4 \%)$ patients had a family history of BD. The type of BD was I in $16(69.6 \%)$ and II in 7 (30.4\%) patients. The first admission occurred during pregnancy in $14(60.9 \%)$ patients. Prophylactic treatments including olanzapine or quetiapine were initiated during pregnancy in $10(71.4 \%)$ of these 14 patients. The average timing of the first and the last assessment was $2.65 \pm 1.99$ and $36.70 \pm 11.50$ weeks postpartum, respectively. The mean follow-up period was $33.95 \pm 12.07$ weeks. The mean duration of illness was $7.48 \pm 4.45$ years. Olanzapine was used by 14 patients, while quetiapine was used by nine. The daily doses were $7.50 \pm 2.59 \mathrm{mg}$ (range, 5-12.5) for olanzapine and $177.78 \pm 97.18 \mathrm{mg}$ (range, 50-400) for quetiapine.

Six (26.1\%) patients experienced a new mood episode during the follow-up period (depressive in two patients, manic in three patients, and hypomanic in one patient). The recurrence rate in patients who received quetiapine and olanzapine was $22.2 \%(n=2)$ and $28.6 \%(n=4)$, respectively. Recurrence was observed between 6 and 32 weeks after childbirth. Table 1 shows the demographic and clinical characteristics of patients with and without a new mood episode. Both groups were similar in terms of age at the time of assessment, educational level, parity, employment status, type of BD, and experience of a mood episode during the last pregnancy. Family history of $\mathrm{BD}$ was significantly higher in the group with a new mood episode. Patients who experienced recurrence during the postpartum period had significantly earlier onset of the disorder, longer duration of illness, and a greater number of mood episodes in the past.

\section{Discussion}

To our knowledge, this was the largest study to examine the use of olanzapine and quetiapine as monotherapy in the prevention of recurrence of bipolar mood episodes in postpartum women to date. Case reports or case series on this subject have been published previously. ${ }^{17-19}$ In our sample, the incidence of recurrent mood episodes was $26.9 \%$. Moreover, the risk of recurrence was similar in patients who received olanzapine or quetiapine. In agreement with these results, a meta-analysis by Wesseloo et al. $^{9}$ found that new mood episodes were observed in $29 \%$ of postpartum women with BD who used prophylactic pharmacotherapy, versus $65 \%$ of medication-free patients. Among different drugs, the most extensive scientific evidence is available on the efficacy of lithium in the prevention of new mood episodes in the postpartum period. ${ }^{11,12}$ The recurrence rate in postpartum patients using lithium was reported to be $20.3 \% .{ }^{11}$ In other words, lithium appears to be the gold-standard medication with regard to efficacy in the prophylactic treatment of bipolar mood episodes during the postpartum period. However, concerns regarding its safety in breastfed infants has led to a search for pharmacotherapeutic alternatives for these patients. If the findings of the current study are confirmed by further research, olanzapine and quetiapine may be good alternatives to lithium, due to their better safety parameters during lactation. ${ }^{13,20}$

Limited studies have examined the factors associated with recurrence of bipolar mood episodes during the 
Table 1 Sociodemographic and clinical characteristics of postpartum women with and without a new mood episode

\begin{tabular}{|c|c|c|c|}
\hline & $\begin{array}{l}\text { Women with a new } \\
\text { mood episode } n=6\end{array}$ & $\begin{array}{l}\text { Women without a new } \\
\text { mood episode } n=17\end{array}$ & $\mathrm{p}$-value \\
\hline Age at assessment, mean \pm SD, years & $31.83 \pm 2.31$ & $29.88 \pm 4.91$ & $0.365 *$ \\
\hline Age at disorder onset, mean $\pm \mathrm{SD}$, years & $19.66 \pm 2.06$ & $24.06 \pm 4.64$ & $0.038 *$ \\
\hline Duration of disorder, mean $\pm S D$, years & $11.83 \pm 3.06$ & $5.94 \pm 3.83$ & $0.003 *$ \\
\hline Number of previous mood episodes, mean \pm SD & $4.17 \pm 1.94$ & $2.53 \pm 1.28$ & $0.028 *$ \\
\hline Education, n (\%) & & & $0.424^{\dagger}$ \\
\hline Primary & $5(83.3)$ & $11(64.7)$ & \\
\hline Secondary & $0(0)$ & $4(23.5)$ & \\
\hline Higher & $1(16.7)$ & $2(11.8)$ & \\
\hline Employment status, n (\%) & & & $1.000^{+}$ \\
\hline Unemployed & $6(100)$ & $15(88.2)$ & \\
\hline Primiparity, n (\%) & $2(33.3)$ & $8(47.1)$ & $0.660^{+}$ \\
\hline Family history of BD, $\mathrm{n}(\%)$ & $4(66.7)$ & $3(17.6)$ & $0.045^{\ddagger}$ \\
\hline Type of BD, n (\%) & & & $1.000^{+}$ \\
\hline i & $4(66.7)$ & $12(70.6)$ & \\
\hline II & $2(33.3)$ & $5(29.4)$ & \\
\hline Mood episode during last pregnancy & $2(33.3)$ & $2(14.3)$ & 0.549 \\
\hline
\end{tabular}

$\mathrm{BD}=$ bipolar disorder; SD = standard deviation.

${ }^{*} t$ test; ${ }^{\dagger} \chi^{2}$ test; ${ }^{\ddagger}$ Fisher's exact test.

postpartum period. The fact that early onset of BD can increase the risk of new mood episodes after childbirth has been stated consistently. ${ }^{2,8,21}$ Jones et al. ${ }^{22}$ reported that a family history of BD may trigger puerperal episodes in patients, which is supported by data from the current study. Our data also suggest that women who experienced postpartum mood episodes had a longer duration of illness and higher number of previous episodes, which may have resulted from earlier onset of BD. Data in the literature on the type of $\mathrm{BD}$ as a possible associated factor is controversial. ${ }^{8,9}$ In our sample, the proportions of patients with BD-I and BD-II disorders were similar in postpartum women with and without new mood episodes.

Previously, some authors reported that the onset of mood symptoms during pregnancy may negatively affect the tendency to development of postpartum mood episodes. ${ }^{2,3,21}$ In the current sample, although the recurrence of mood episodes was about 2.5-fold higher in patients who experienced an episode during pregnancy, the difference did not reach statistical significance, most likely due to the small sample size. A history of prior postpartum episodes is expected to be associated with elevated incidence of new mood episodes during the postpartum period. However, it is unclear whether this factor contributes to the risk of recurrence of bipolar mood episodes after childbirth, since most available studies have not reported any data on the history of postpartum episodes. ${ }^{9}$ We did not examine the effect of this factor, because the small number of patients who experienced postpartum episodes prior to the last pregnancy (when they had a diagnosis of $\mathrm{BD}$ ) did not permit statistical analysis.

The retrospective design, lack of blinding to pharmacotherapy, lack of a control group that did not take any prophylactic medication, and small sample size are the principal limitations can affect interpretation of the findings of the current study. Ethical and legal issues appear to be the main reasons for the lack of prospective randomized controlled studies in the literature. The current study was carried out in a single hospital; therefore, its results cannot be generalized to all patients with BD. Despite these limitations, our results may encourage the use of olanzapine and quetiapine in the prevention of development of a new mood episode in postpartum women with BD. Further studies with larger sample sizes should be conducted to confirm these findings. In addition, comparative studies of lithium versus olanzapine or quetiapine may be useful for better evaluation of the results.

\section{Disclosure}

The authors report no conflicts of interest.

\section{References}

1 Merikangas KR, Jin R, He JP, Kessler RC, Lee S, Sampson NA, et al. Prevalence and correlates of bipolar spectrum disorder in the national comorbidity surevy replication. Arch Gen Psychiatry. 2011;68:241-51.

2 Viguera AC, Tondo L, Koukopoulos AE, Reginaldi D, Lepri B, Baldessarini RJ. Episodes of mood disorders in 2,252 pregnancies and postpartum periods. Am J Psychiatry. 2011;168:1179-85.

3 Freeman MP, Smith KW, Freeman SA, McElroy SL, Kmetz GF, Wright $R$, et al. The impact of reproductive events on the course of bipolar disorder in women. J Clin Psychiatry. 2002;63:284-7.

4 Di Florio A, Gordon-Smith K, Forty L, Kosorok MR, Fraser C, Perry A, et al. Stratification of the risk of bipolar disorder recurrences in pregnancy and postpartum. Br J Psychiatry. 2018;213:542-7.

5 Pope CJ, Mazmanian D, Sharma V. Bipolar disorder. In: Uguz F, editor. Psychiatric disorders during the postpartum period in light of current advances. New York: Nova Science; 2016. p. 11-27.

6 Biel MG, Peselow E, Mulcare L, Case BG, Fieve R. Conrinuation versus discontinuation of lirhium in recurrent bipolar illness: a naturalistic study. Bipolar Disord. 2007;9:435-42.

7 Belzeaux R, Sanguinetti C, Murru A, Verdolini N, Pacchiarotti I, Mazzei DH, et al. Pharmacotherapy for the peripartum management of bipolar disorder. Expert Opin Pharmacother. 2019;20:1731-41. 
8 Maina G, Rosso G, Aguglia A, Bogetto F. Recurrence rates of bipolar disorder during the postpartum period: a study on 276 medicationfree Italian women. Arch Womens Ment Health. 2014;17:367-72.

9 Wesseloo R, Kamperman AM, Munk-Olsen T, Pop VJ, Kushner SA, Bergink V. Risk of postpartum relapse in bipolar disorder and postpartum psychosis: a systematic review and meta-analysis. Am J Psychiatry. 2016;173:117-27.

10 Khan SJ, Fersh ME, Ernst C, Klipstein K, Albertini ES, Lusskin SI. Bipolar disorder in pregnancy and postpartum: principles of management. Curr Psychiatry Rep. 2016;18:13.

11 Uguz F. Pharmacological prevention of mood episodes in women with bipolar disorder during the perinatal period: a systematic review of current literature. Asian J Psychiatry. 2020;52:102145.

12 Fornaro M, Maritan E, Ferranti R, Zaninotto L, Miola A, Anastasia A et al. Lithium exposure during pregnancy and the postpartum period: a systematic review and meta-analysis of safety and efficacy outcomes. Am J Psychiatry. 2020;177:76-92.

13 Uguz F, Sharma V. Mood stabilizers during breastfeeding: a systematic review of the recent literature. Bipolar Disord. 2016;18:325-33.

14 Yatham LN, Kennedy SH, Parikh SV, Schaffer A, Bond DJ, Frey BN, et al. Canadian Network for Mood and Anxiety Treatments (CANMAT) and International Society for Bipolar Disorders (ISBD) 2018 guidelines for the management of patients with bipolar disorder. Bipolar Disord. 2018;20:97-170.
15 Malhi GS, Bassett D, Boyce P, Bryant R, Fitzgerald PB, Fritz K, et al. Royal Australian and New Zealand College of Psychiatrists clinical practice guidelines for mood disorders. Aust $\mathrm{N} Z \mathrm{~J}$ Psychiatry. 2015;49:1087-206

16 Spitzer RL, Williams JBW, Gibbon M, First MB. Structured Clinical Interview for DSM-IV Clinical Version (SCID-I/CV). Washington: American Psychiatric Press; 1997.

17 Uguz F. Prophylactic use of olanzapine and quetiapine from pregnancy to the postpartum period in women with bipolar disorder: a case series. J Matern Fetal Neonatal Med. 2017;30:2569-71.

18 Sharma V, Smith A, Mazmanian D. Olanzapine in the prevention of postpartum psychosis and mood episodes in bipolar disorder. Bipolar Disord. 2006;8:400-4.

19 Sharma V, Sommerdyk C. Lamotrigine in the prevention of bipolar II postpartum depression. Prim Care Comp CNS Disord. 2016;18(6).

20 Uguz F. Second-generation antipsychotics during the lactation period: a comparative systematic review on infant safety. J Clin Psychopharmacol. 2016;36:244-52.

21 Akdeniz F, Vahip S, Pirildar S, Vahip I, Doganer I, Bulut I. Risk factors associated with childbearing-related episodes in women with bipolar disorder. Psychopathology. 2003;36:234-8.

22 Jones I, Craddock N. Familiality of the puerperal trigger in bipolar disorder: results of a family study. Am J Psychiatry. 2001;158: 913-7. 


\section{Corrigendum}

http://dx.doi.org/10.1590/1516-4446-2021-0027

We regret to inform that an error passed unnoticed in the article titled "Olanzapine and quetiapine in the prevention of a new mood episode in women with bipolar disorder during the postpartum period: a retrospective cohort study" (http://dx. doi.org/10.1590/1516-4446-2020-1629), by Faruk Uguz \& Aysegul Kirkas, published in the Brazilian Journal of Psychiatry in April 2021 in ahead of print mode. The error appears in Table 1, in the header of the second data column: "Women with a new mood episode $\mathrm{n}=17$ " should read "Women without a new mood episode $\mathrm{n}=17$." Below we reproduce the revised, correct version of Table 1:

Table 1 Sociodemographic and clinical characteristics of postpartum women with and without a new mood episode

\begin{tabular}{|c|c|c|c|}
\hline & $\begin{array}{l}\text { Women with a new } \\
\text { mood episode } n=6\end{array}$ & $\begin{array}{l}\text { Women without a new } \\
\text { mood episode } n=17\end{array}$ & $p$-value \\
\hline Age at assessment, mean \pm SD, years & $31.83 \pm 2.31$ & $29.88 \pm 4.91$ & $0.365^{\star}$ \\
\hline Age at disorder onset, mean $\pm S D$, years & $19.66 \pm 2.06$ & $24.06 \pm 4.64$ & $0.038^{*}$ \\
\hline Duration of disorder, mean $\pm S D$, years & $11.83 \pm 3.06$ & $5.94 \pm 3.83$ & $0.003^{*}$ \\
\hline Number of previous mood episodes, mean \pm SD & $4.17 \pm 1.94$ & $2.53 \pm 1.28$ & $0.028^{*}$ \\
\hline Education, n (\%) & & & $0.424^{\dagger}$ \\
\hline Primary & $5(83.3)$ & $11(64.7)$ & \\
\hline Secondary & $0(0)$ & $4(23.5)$ & \\
\hline Higher & $1(16.7)$ & $2(11.8)$ & \\
\hline Employment status, n (\%) & & & 1.000 \\
\hline Unemployed & $6(100)$ & $15(88.2)$ & \\
\hline Primiparity, n (\%) & $2(33.3)$ & $8(47.1)$ & $0.660^{\ddagger}$ \\
\hline Family history of $\mathrm{BD}, \mathrm{n}(\%)$ & $4(66.7)$ & $3(17.6)$ & $0.045^{\ddagger}$ \\
\hline Type of BD, n (\%) & & & 1.000 \\
\hline 1 & $4(66.7)$ & $12(70.6)$ & \\
\hline II & $2(33.3)$ & $5(29.4)$ & \\
\hline Mood episode during last pregnancy & $2(33.3)$ & $2(14.3)$ & $0.549^{\ddagger}$ \\
\hline
\end{tabular}

$\mathrm{BD}=$ bipolar disorder; $\mathrm{SD}=$ standard deviation .

$* t$ test; ${ }^{\dagger} \chi^{2}$ test; ${ }^{*}$ Fisher's exact test. 